\title{
Ovary resorption in the Norway lobster (Nephrops norvegicus) and its possible causes with special reference to sperm storage
}

\author{
Carola Becker ${ }^{1 *}$ (1) Jaimie T. A. Dick ${ }^{1,2}$, E. Mánus Cunningham ${ }^{1}$, Mathieu Lundy ${ }^{3}$, Ewen Bell ${ }^{4}$, Lawrence Eagling ${ }^{1}$ \\ and Julia D. Sigwart ${ }^{1}$
}

\begin{abstract}
The Norway lobster, Nephrops norvegicus, is an important fisheries species in the North-East Atlantic area. In some circumstances, mature females of Nephrops norvegicus can resorb their ovary rather than completing spawning, but the implications of this phenomenon to reproductive biology and fisheries sustainability are not known. To understand after effects of ovary resorption, we studied long-term demographic data sets (1994-2017) collected from the western Irish Sea and the North Sea. Our considerations focused on potential correlations among the frequency of resorption, female insemination, and body size of resorbing females. Resorption was continuously rare in the western Irish Sea (less than 1\%); whereas much higher rates with considerable year-to-year variation were observed in the North Sea (mean 9\%). Resorption started in autumn after the spawning season (summer) had passed. The frequency stayed high throughout winter and declined again in spring. As sperm limitation can occur in male-biased fisheries, we expected a lack of insemination could be responsible for resorption, but affected females were indeed inseminated. Resorbing females were significantly larger than other sexually mature females in the North Sea, but the opposite trend was observed in the western Irish Sea. It is therefore possible that other, environmental factors or seasonal shifts, may trigger females to resorb their ovaries instead of spawning. Resorption may as well represent a natural phenomenon allowing flexibility in the periodicity of growth and reproduction. In this sense, observations of annual versus biennial reproductive cycles in different regions may be closely linked to the phenomenon of ovary resorption.
\end{abstract}

\section{Introduction}

Ovary resorption, also termed oosorption or reabsorption, is a common, but poorly understood phenomenon known in several species of clawed lobsters [1-4]. The process of resorbing ovaries instead of spawning allows females to recycle and thereby conserve nutrients accumulated in their ovaries [4]. Becker et al. [5] recently studied ovary maturation in the Norway lobster, Nephrops norvegicus, and distinguished two different pathways in the female reproductive cycle (Fig. 1a).

\footnotetext{
*Correspondence: carolabecker.germany@gmail.com

${ }^{1}$ Queen's University Marine Laboratory, 12-13 The Strand, Portaferry BT22 1PF, Northern Ireland, UK
}

Full list of author information is available at the end of the article
The resorption of a few remaining oocytes that were not released during spawning is a regular process of the reproductive cycle and is observed in recently spawned, ovigerous (berried) females (termed "partial resorption", see [5]). However, the full resorption of ovaries is rather an interruption of the regular reproductive cycle: affected females do not spawn, but skip the reproductive season and completely resorb their ovaries ("full resorption", see [5]). Resorption has been studied in the American lobster Homarus americanus [6], the European lobster H. gammarus [7] and the Norway lobster N. norvegicus [8]. Herrick [9] described ovaries in this condition as "marbled" ("green and lemon coloured") and Allen [1] observed a darkening of the hemolymph in resorbing females, which results in tainted specimens ("black lobsters") that were 


\section{a}
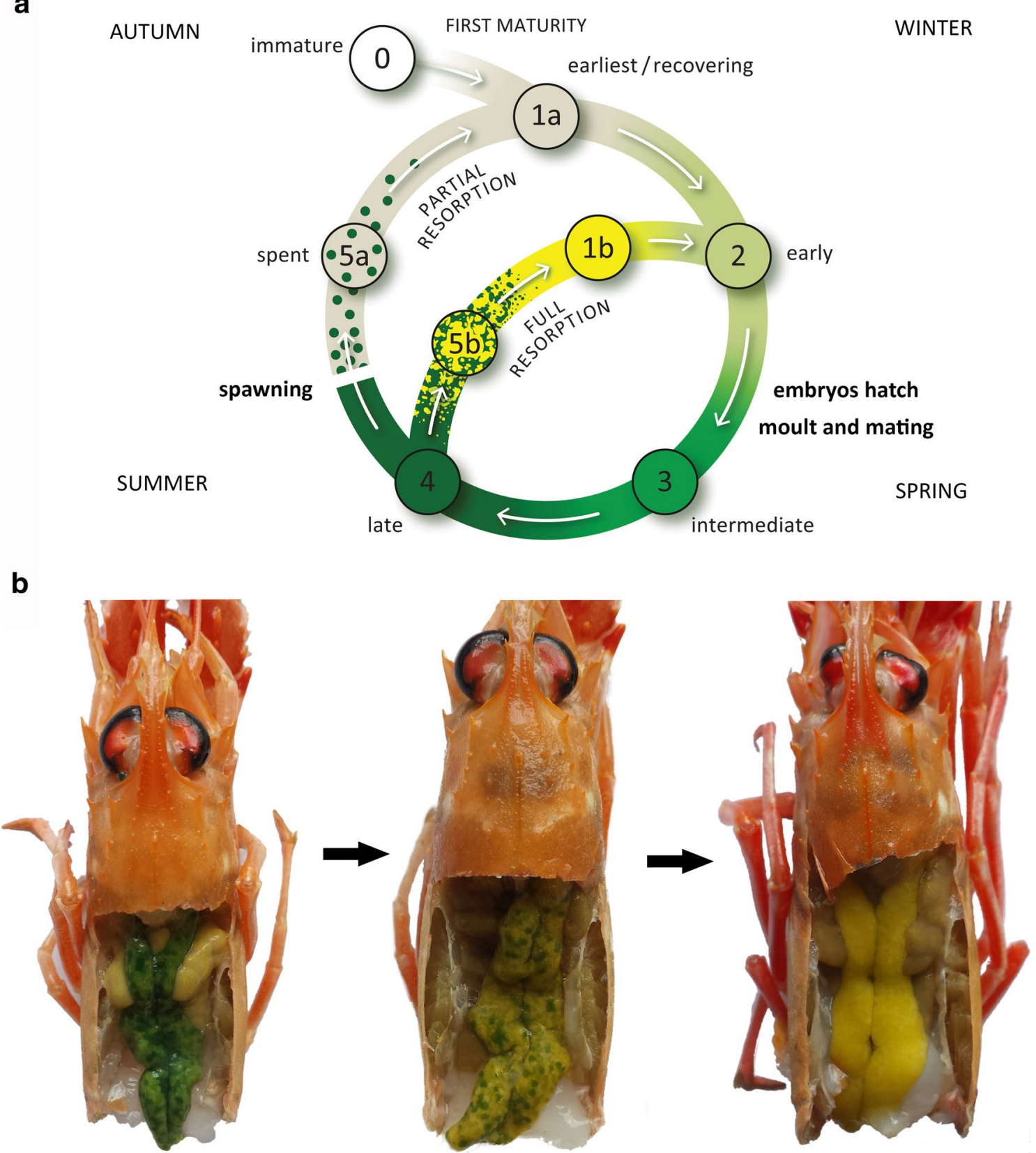

Fig. 1 The female reproductive cycle of Nephrops norvegicus. a In the regular cycle, ovaries develop through darkening shades of green (stages 1 a to 4). Females in late ovary maturation (stage 4) spawn in summer and resorb few remaining oocytes in the spent ovary afterwards (partial resorption, stage 5a). However, a proportion of females proceed along a different pathway once maturation is almost complete (stage 4). Instead of spawning, these females completely resorb the green yolk in their ovaries indicated by increasing shades of yellow (stages $5 \mathrm{~b}$ and $1 \mathrm{~b}$ ). These females skip one reproductive cycle and reenter the regular cycle presumably at stage 2 . $\mathbf{b}$ The process of full resorption (5b to $1 \mathbf{b})$ is characterised by a mottled appearance with a mix of green and yellow in the ovary. With the progressive resorption of the green yolk, the proportion of yellow increases until all the green yolk has disappeared in stage 1b. The license number is 4926480336055

not marketable [1]. The conundrum of resorbing ovaries is therefore relevant to both fundamental reproductive biology and fisheries economics.
Females undergoing full ovary resorption, recycling nutrients from the ovaries instead of spawning, were first observed in the European lobster, H. gammarus, in caught lobsters maintained in cages floating at the water 
surface. Females did not spawn in the holding cages, which was suggested to be due to oxygen deprivation under holding conditions [9]. Full ovary resorption, however, also occurs under natural conditions and several possible causes have been discussed in the literature $[2,7$, 8]. This process has been linked to hormone deprivation, unsuitable environmental conditions, or a lack of insemination $[2-4,10]$.

Sperm depletion, limitation and exhaustion have been observed to occur in intensively male-biased fisheries of other decapod crustaceans [11]. If the sex ratio is skewed in favour of females, those females might not succeed in finding a mate or males may suffer sperm depletion after multiple copulations and be unable to allocate sufficient amounts of sperm to each female. In this context, Chapman [12] suggested that a lack of insemination may cause full ovary resorption in $N$. norvegicus.

Another possible cause for ovary resorption was first mentioned by Bailey [10] who studied the reproductive cycle of $N$. norvegicus in the Firth of Clyde (Scotland): he supposed that the maturation of ovaries may take longer in larger (older) females than the regular annual cycle. Thus, spawning would occur slightly later with every passing cycle as the larger/older ovary took longer to develop. Over the years, this delay may accumulate to a point where ovary maturation would be completed too late in the season for successful spawning. Instead of producing a brood with low chances of survival, females may resorb their ovaries to recycle nutrients. Ovary resorption in one season would thereby "reset the clock" [10] for the next season and allow females to restart ovary maturation earlier in the following year.

To date, there is no evidence to firmly support any of these ideas, and the consequences of full ovary resorption are likewise unknown. Females which resorb their ovaries skip a reproductive cycle instead of spawning, and this is alarming as populations with high levels of resorption may have a reduced reproductive capacity in comparison to populations where resorption is rare or absent. Recently established information about the reproductive cycle [5], and the consistent identification of resorption in $N$. norvegicus, has provided an opportunity to test these hypotheses in a more robust way.

In $N$. norvegicus, ovary maturation is apparent by a transition from light to darkening shades of green representing the accumulation of yolk, which has a green colour in fresh ovarian tissue in several species of lobsters (e.g. $[2,13])$. An ovary undergoing full resorption appears mottled and shows a mix of green and yellow shades (Fig. 1b) due to the simultaneous presence of vitellogenic (green) and resorbing (yellow) oocytes. Post-spawning (spent) ovaries also look mottled and show green spots (representing unspawned vitellogenic oocytes) but can be distinguished from full premature resorption by an otherwise white to light cream, deflated ovary. Those two different stages are easily identified as females undergoing full resorption never carry eggs, while females under partial resorption are always ovigerous [5]. On the microscopic level, resorbing ovaries are characterised by the presence of atresic (resorbing) oocytes [5]. Symonds [14] and Farmer [13] recognised mottled ovaries as a separate stage first, but did not differentiate between partial and full resorption. The only available studies that make this distinction in N. norvegicus are by de Figueiredo [8] and Bailey [10]. The percentage of females undergoing full resorption instead of spawning varies among different geographical regions $[10,13]$. For example, Icelandic $N$. norvegicus only showed $0-4 \%$ of females with resorbing ovaries during the spawning season (May 1990-1992 and 2006-2010) [15]. The seasonal dynamics of full ovary resorption are not understood as biological monitoring coincides with the fishing seasons and some surveys are conducted only once a year [16].

\section{Problems and aims}

The first goal of this study was to better understand ovary resorption in $N$. norvegicus by assessing the temporal occurrence of this phenomenon in long-term data sets collected during trawl surveys in the western Irish Sea and from routine fishery sampling from the Farn Deeps region of the North Sea. The second goal of this study was to test possible causes of ovary resorption. To assess whether ovary resorption was caused by a lack of insemination, we examined the sperm storage organs of females with resorbing ovaries for the presence/absence of spermatophores using histological methods and light microscopy. We then tested whether ovary resorption is more common in larger than in smaller females to reveal whether resorption may be caused by a deceleration of ovary maturation in older (larger) females.

\section{Materials and methods Long-term data sets}

The Agri-Food and Biosciences Institute (AFBI, Northern Ireland, U.K.) have been collecting Nephrops length and maturity data during trawl surveys at different stations in the western Irish Sea (ICES Functional Unit 15) from 1994 onwards (Additional file 1: Fig. S1). Samples were taken on board the R.V. Corystes using an Otter trawl (mesh size $10 \mathrm{~mm}$ ) in tows of $30 \mathrm{~min}$ at a trawl speed between 2.4 and 2.7 knots. The whole catch was weighed and a random subsample of approximately $5 \mathrm{~kg}$ was taken for detailed analysis. All specimens in the subsample were sorted by sex. Female maturity was assessed through ovary colour using a six stage scale (Table 1 ). The carapace length $(\mathrm{CL})$ of all females in each stage 
Table 1 Conversion of the Agri-Food and Biosciences Institute (AFBI) and the Centre of Environment, Fisheries and Aquaculture Science (CEFAS) ovary staging scales into the revised staging scale as proposed by Becker et al. [5]

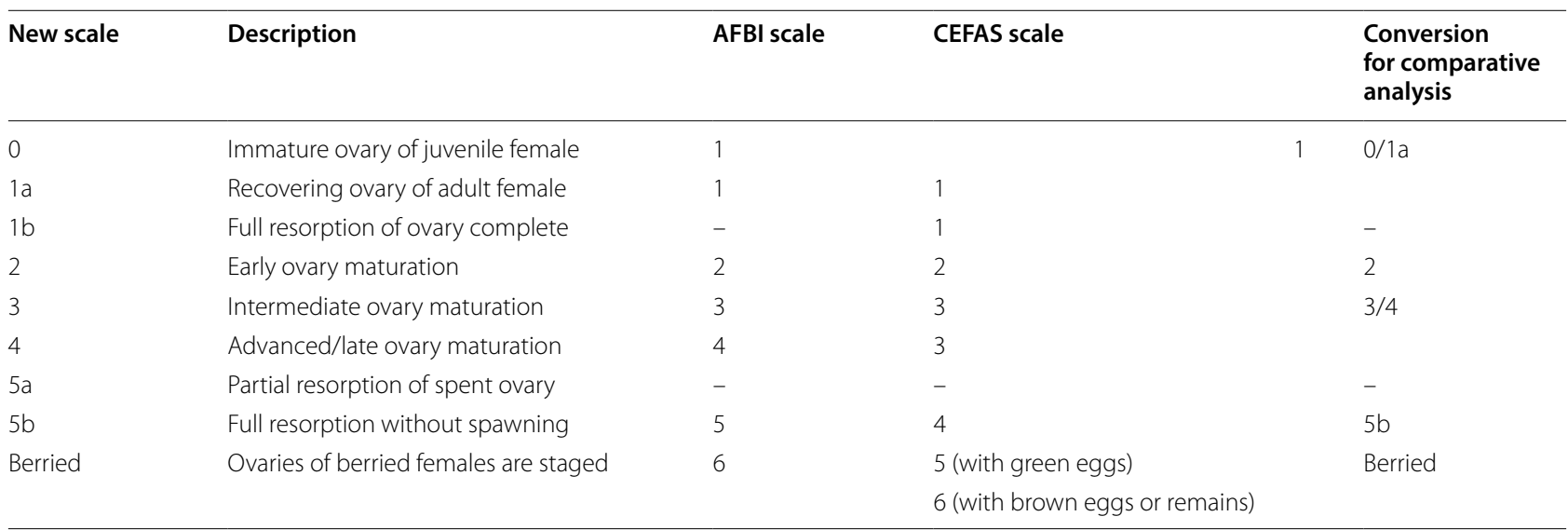

This new scale differentiates between immature juvenile females (stage 0 ) on the one hand and adult females with recovering or earliest maturing ovaries on the other hand (stage 1a). It also discriminates between females with spent ovaries undergoing partial resorption (stage $5 \mathrm{a}$ ) and females which failed to spawn and undergo full resorption (stages $5 b-1 b$ ). To allow comparative analyses of the AFBI and CEFAS data, the stages assessed using their respective maturity scales were converted into a simplified scale adapted from Becker et al. [5]. The ovaries of berried females are neither staged by AFBI nor by CEFAS. Stage 5a, which only occurs in recently spawned females, is therefore not recognised in their data. The AFBI staging scale does also not recognize fully resorbed ovaries (stage $1 \mathrm{~b}$ ) as a separate stage. Stage $1 \mathrm{~b}$ is assigned to stage 1 according to the maturity scale used by CEFAS

were measured using digital calipers (with a precision of $0.01 \mathrm{~mm}$ ). The data were mainly collected in spring and summer between 1994 and 2016 (Fig. 2). Spring surveys were conducted in April from 1994 to 2007, 2009 and 2010, while the one in 2008 took place in May. Additional samples were taken in June 1996. Regular summer surveys were undertaken from 1997 to 2016 (but not in 2013) and took place in August every year, or in late July in 2009 (Fig. 2). Additional autumn data were available from the mid-1990s, in October from 1994 and 1995, and September 1996 (Fig. 2). Samples for light microscopic studies were collected during the AFBI summer survey in the western Irish Sea from 9 to 13 August 2016.

Data on female stages collected in the Farn Deeps region of the North Sea (ICES Functional Unit 6) from trawl-caught commercial catch samples from 1998 to 2017 were made available by the Centre of Environment, Fisheries and Aquaculture Science (CEFAS, UK). All specimens in the subsample were sorted by sex and the CL was measured using callipers (with a precision of $1 \mathrm{~mm}$ ). A five stage scale was used to assess female maturity through ovary colour (Table 1 ).

\section{Additional samples for microscopic analysis}

Samples from Strangford Lough (Northern Ireland, U.K.; ICES Functional Unit 15) were creel-caught by a local fisherman in May 2016 at depths from 10 to $25 \mathrm{~m}$ (Tip Reef, $54^{\circ} 27^{\prime} 55 \mathrm{~N} 05^{\circ} 34^{\prime} 80 \mathrm{~W}$ ). Additional samples from creel catches from the Northumberland Coast in the Farn Deeps region (North East England, U.K.) were provided by Kilkeel/Whitby Seafoods in 2017. A total of 163 females was staged in February 2017 and 189 females in March 2017.

These samples were taken to obtain fresh (living) material for careful examination and documentation in the laboratory, while previous samples were analysed under on-board conditions.

The minimum size of specimens examined was $34 \mathrm{~mm}$ $\mathrm{CL}$ in Strangford Lough (western Irish Sea) and $30 \mathrm{~mm}$ $\mathrm{CL}$ in the Farn Deeps region of the North Sea. Juvenile females were therefore not represented in these samples. The CL of females was measured using calipers (with a precision of $1 \mathrm{~mm}$ ), and maturity was staged in dissected females using an eight stage scale ([5]; Table 1).

\section{Data analysis and illustrations}

The maturity scales to assess female ovary stages used by AFBI and CEFAS differ: the former is based on Farmer [13], while the latter is adapted from an ICES recommendation [17]. For comparative analyses, the AFBI and CEFAS scales were converted into a unified scale (following [5]; Table 1).

The commercial catch of $N$. norvegicus in the Farn Deeps is predominantly a winter fishery (SeptemberMarch), targeting males during the time when females are hidden in burrows; thus, the months of May to August were not covered in the CEFAS data sets. Conversely, AFBI surveys to determine total stock demographics are mainly conducted in spring and summer (Fig. 2).

Data collected in different months were combined to facilitate comparisons between the populations. Across 
all survey years, "spring" samples combine data from March and April from North Sea, and represent April in the western Irish Sea. "Autumn" data are represented by sampling in September (western Irish Sea) or October (North Sea). "Summer" data from July or August are available from large scale annual surveys in the western Irish Sea but not in the North Sea. "Winter" data from a longer period, October-February were the primary sampling data for the North Sea.

For line diagrams illustrating the size distribution for each maturity stage in different seasons, only specimens between $10 \mathrm{~mm} \mathrm{CL}$ and $50 \mathrm{~mm} \mathrm{CL}$ for the AFBI data and up to $60 \mathrm{~mm}$ CL for the CEFAS data were included in statistical comparisons of size and size distributions.

\section{Microscopic analysis}

A total of 13 females, six of them with ovaries undergoing full resorption, were used for microscopic analysis (Additional file 2: Table S2). The female sperm storage organ was dissected and preserved in Bouin's solution or in "Susa Heidenhain" (MORPHISTO ${ }^{\circledR}$ Evolutionsforschung und Anwendung GmbH, Frankfurt am Main, Germany) for one to three weeks. Susa-fixed samples were then washed in a descending series of ethanol (100\%, 96\%, 90\%, 80\%, 70\%); Bouin-fixed samples were repeatedly washed in $70 \%$ ethanol. Samples were subsequently stored in $70 \%$ ethanol before they were used. For decalcification, specimens were treated in a neutrally buffered 10\% solution of Ethylenediaminetetraacetic acid (EDTA) in water for $48-72 \mathrm{~h}$. Specimens were subsequently dehydrated through a series of ascending ethanol solutions, infiltrated in an automate (Shandon Hypercenter XP, Thermo Fisher Scientific, Waltham, Massachusetts, USA), and embedded in paraffin wax blocks. Transverse sections of the spermatheca were prepared at 6-8 $\mu \mathrm{m}$ using a Leica RM2255 rotary microtome (Leica Microsystems GmbH, Wetzlar, Germany) and stained using a trichromatic Masson-Goldner "light green" stain

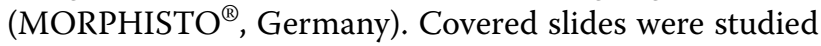
and photographed using an Olympus BX41 compound microscope equipped with an Olympus E600 camera. Images were processed and assembled to figure plates in Adobe Photoshop software version CS5.1.

\section{Results}

\section{Ovary resorption in Irish Sea and North Sea fishing grounds}

The temporal distribution of female maturity stages is illustrated in a histogram using AFBI summer data and CEFAS data from October to February as other months were not sampled annually (Fig. 3). The mean percentage of females with ovaries undergoing full resorption was $<1 \%$ each year among stations in the western Irish
Sea (mean 0.5\%, summer 1997-2016; Fig. 3) compared to a mean of $8.8 \%$ of across all years among samples from the Farn Deeps of the North Sea (winter 20002016; Fig. 3). Resorption (stage 5b) peaked at $21 \%$ in 2003 in samples from the North Sea. Month-to-month patterns in the North Sea (combining winter data from each month across all available years) show an increase in maturing stages (stage 3/4) as earlier stages (stage $0 / 1 \mathrm{a} / 1 \mathrm{~b}$, stage 2 ) decrease, but also a steady occurrence of mottled, resorbing ovaries (stage 5b; Fig. 4). The mean percentage of stage $5 \mathrm{~b}$ is highest in November and December (10\%) and ceases in the following months with $8 \%$ in January and $7 \%$ in February. The percentage of females with resorbing ovaries (stages $5 \mathrm{~b}$, 1b) was $25 \%(n=163)$ in the additional samples from the Farn Deeps region of the North Sea provided by Whitby Seafoods in February 2017, and 13\% $(n=189)$ in March 2017 (Fig. 5).

Size distributions, mean sizes, and maximum sizes differed considerably between the data collected from populations in the western Irish Sea and the North Sea due to differences in sampling methods and probably also the biology of these two populations (Additional file 3: Fig. S2; Additional file 4: Table S1). The mean size of females undergoing full resorption (stage $5 \mathrm{~b}$ ) was $25.76 \mathrm{~mm} \mathrm{CL}$ and significantly smaller $(\mathrm{p}<0.001)$ than the sexually mature females (stage 4 and berried females combined) in samples from the western Irish Sea (mean CL: $26.35 \mathrm{~mm}$ ). However, in the samples from the North Sea, the opposite trend was observed: females in stage $5 \mathrm{~b}$ had a mean CL of $35.17 \mathrm{~mm}$ and were significantly larger $(\mathrm{p}<0.001)$ than sexually mature females (stage $3 / 4$ and berried females combined) at $33.94 \mathrm{~mm} \mathrm{CL}$. When we resolved the data by seasons, only western Irish Sea samples from spring showed larger sized females in stage $5 b$ than in other sexually mature stages. In spring (April) in the western Irish Sea and in autumn (September/October) in the North Sea, stage 5b females were slightly larger on average than females with maturing to berried ovaries (Figs. 6 and 7). By contrast, in autumn western Irish Sea and spring North Sea samples, the opposite pattern was observed, with mean sizes of females with resorbing ovaries (stage $5 \mathrm{~b}$ ) being slightly smaller than berried females and females in stage 3 and 4 . Material from the North Sea was collected at commercial sizes, while the western Irish Sea was unrestricted; however, there was greater size-stage segregation in the North Sea material. Immature individuals in the North Sea samples are clearly smaller than those with berried or resorbing ovaries (Fig. 7), while the peak of size frequency distributions of all stages largely overlap in the western Irish Sea samples (Fig. 6). 


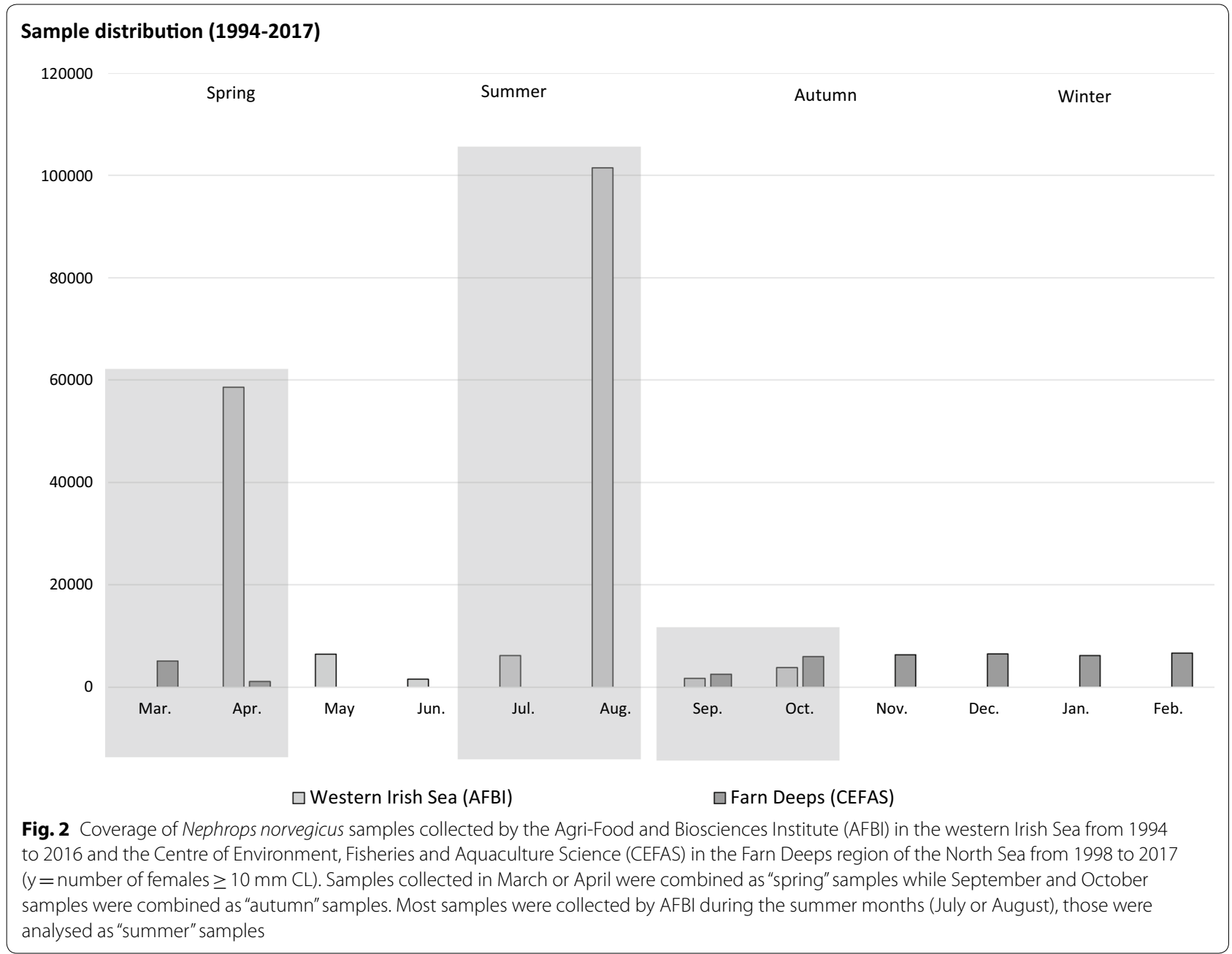

\section{Microscopic observations-a test for insemination}

Females store sperm in a single cuticle-lined sperm storage organ, often called spermatheca. Whether females are inseminated is easily observed in histological sections: inseminated females have spermathecae filled with spermatophores embedded in seminal fluid (Fig. 8a, b) while juvenile sexually immature females that have not mated show completely empty spermathecae (Fig. 8c, d).

The region of the female sternum in the thoracic segments 7 and 8 on the level of the corresponding 4th and 5th pairs of pereiopods is modified for reproductive purposes and leads into an internalized, cuticular spermatheca where sperm is stored. The orifice of the spermatheca consists of an anterior suture ("orifice" [18]) along the longitudinal midline of the sternum and two oblique posterior sutures ("postero-lateral groove" [18]) which correspond to the sternal suture between sternites 7 and 8 (Fig. 9a). The gonopores are situated ventrally on the coxae of the 5 th pereiopods (Fig. 9a).
The spermathecae of all sexually mature females studied herein, were filled with discrete portions of homogeneous, hardened male secretion ("sealant" [19]) containing spermatophores (Fig. 9b-d). A spermatophore was always present in the wide compartment of the spermatheca communicating with the anterior suture of the spermathecal orifice (Figs. $8 \mathrm{a}, \mathrm{b} ; 9 \mathrm{~b}$ ). More posteriorly, the spermathecal lumen is restricted by the bulging $8^{\text {th }}$ thoracic segment (Fig. 9c). The two posterior grooves communicate with the spermathecae in this region. Most posteriorly, the spermatheca forms two small cavities (Fig. 9d), which have been filled with spermatophores in all studied females that were sexually mature (Fig. 9e, f). We did not observe any differences in the content of the spermatheca between females with resorbing ovaries (stage 5b, Fig. 8a, b) and females in other (intermoult) stages (Fig. 9a-f). Among the specimens examined, only very small sexually immature females had empty spermathecae (Fig. 8c, d). 


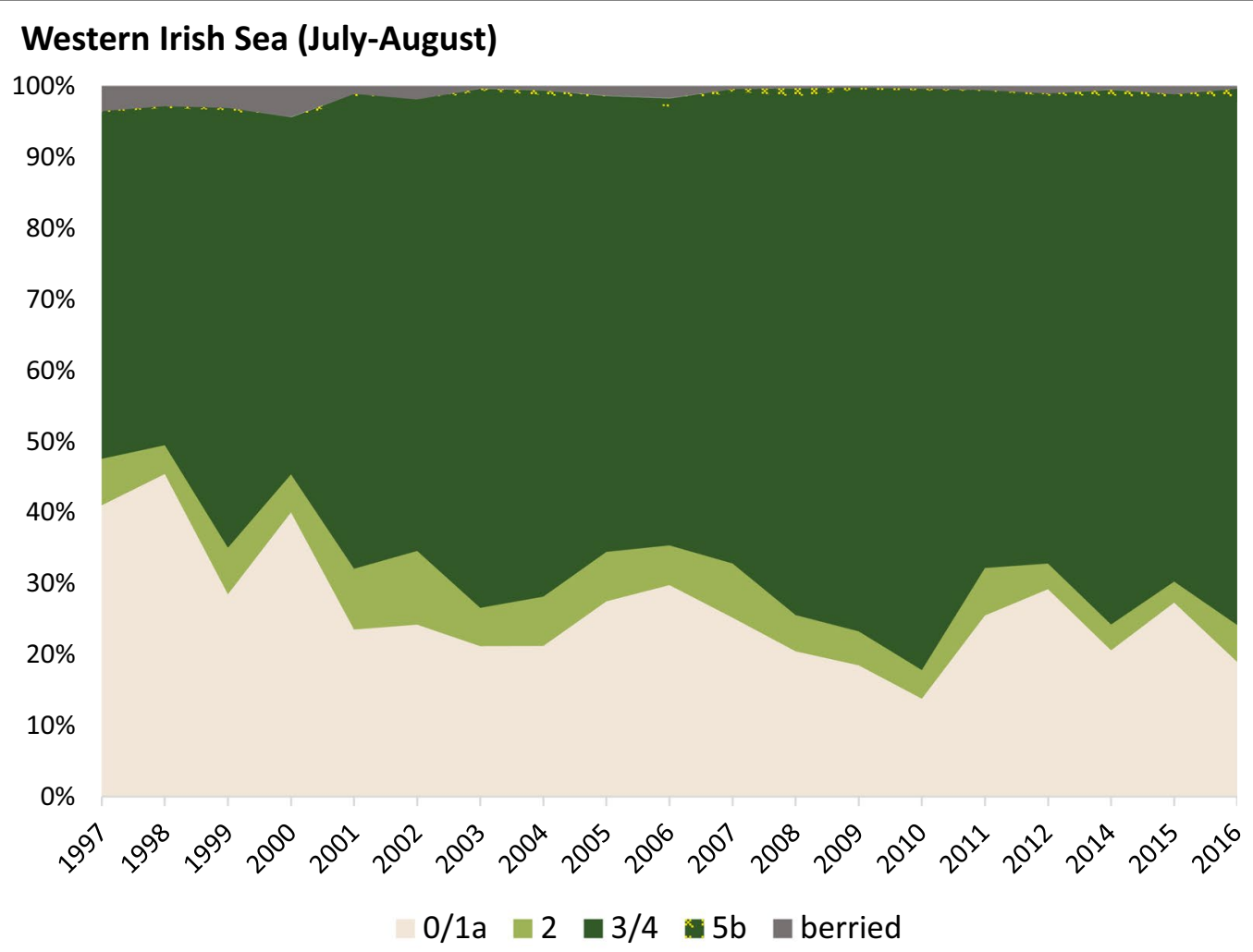

North Sea (October-February)

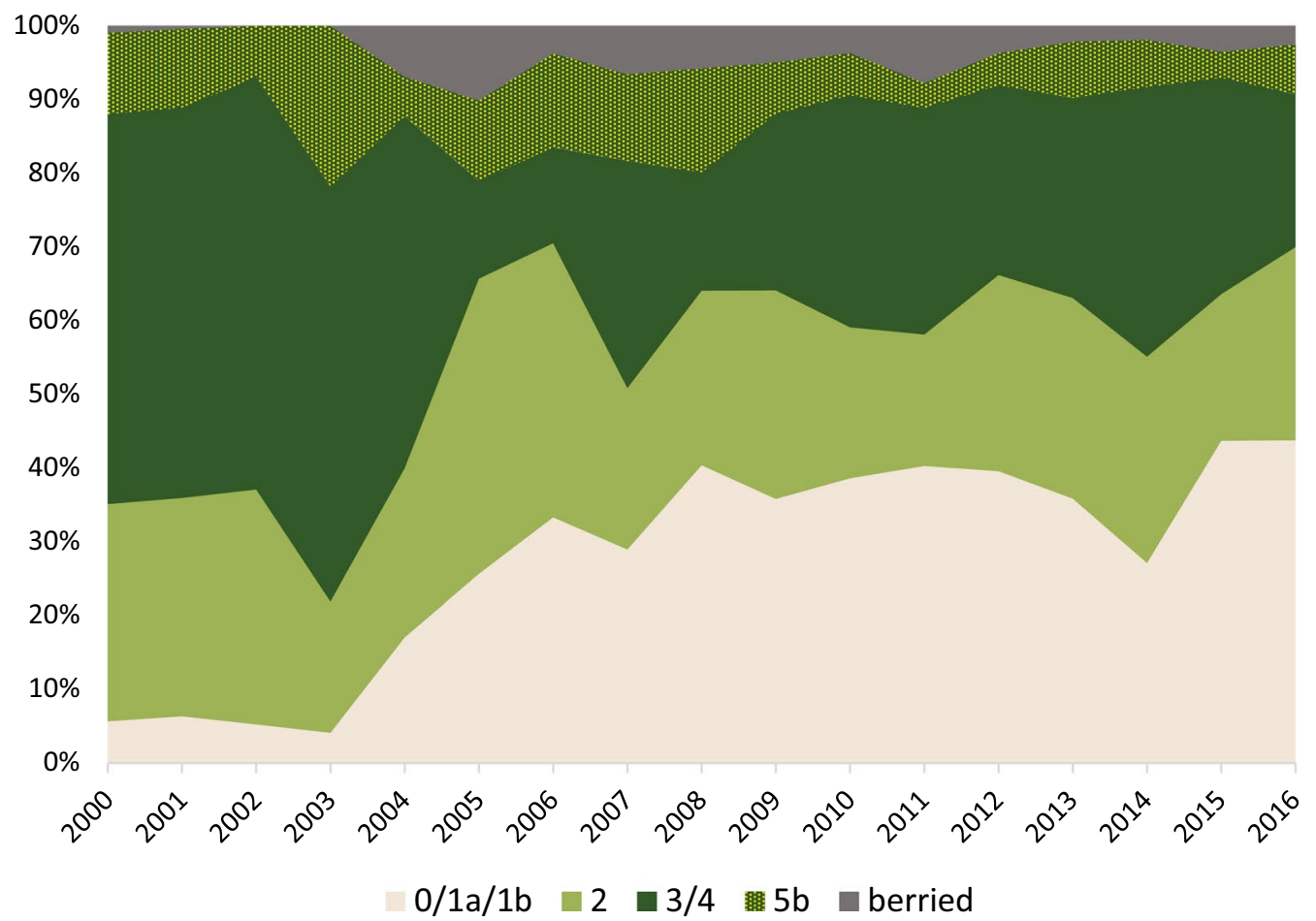

Fig. 3 Temporal distribution of female Nephrops norvegicus maturity stages in samples collected by the Agri-Food and Biosciences Institute (AFBI) in the western Irish Sea from 1994 to 2016 (July-August) and the Centre of Environment, Fisheries and Aquaculture Science (CEFAS) in the Farn Deeps of the North Sea from 1998 to 2017 (October-February). The average incidence of ovary resorption (stage 5b) is very rare in the western Irish Sea (mean $<1 \%)$, while it is considerably higher in the Farn Deeps (mean 8.8\%) 


\section{Seasonality of maturity stages (North Sea)}

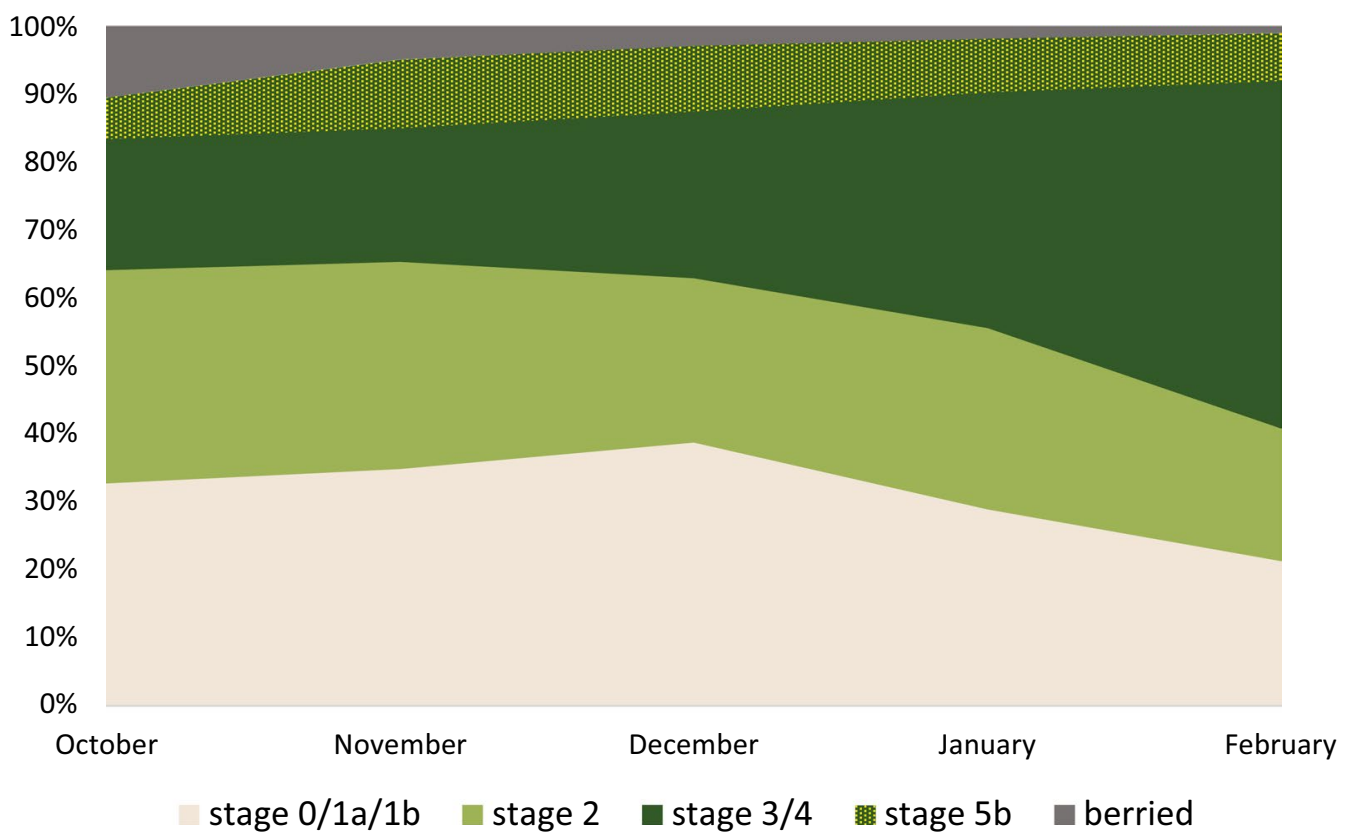

Fig. 4 Seasonal distribution of female Nephrops norvegicus maturity stages across the data collected by the Centre of Environment, Fisheries and Aquaculture Science (CEFAS) from 2000 to 2016 (October-February) in the Farn Deeps of the North Sea. The proportion of females with resorbing ovaries (stage 5b) is highest in November-December

Figure 9g, h show a pre-moult female close to ecdysis, apparent by the presence of a delaminated cuticle (the old cuticle) and a thinner layer of cuticle underneath (the new cuticle). The sealant has eroded and does no longer fill the whole lumen of the spermatheca while spermatophores have disintegrated. The presented sections are from a female sampled in May that did not carry eggs (stage 3). It is not known whether this female had skipped a reproductive cycle or larvae had already hatched.

\section{Discussion}

Fishery sustainability depends on the long-term reproductive viability of a population, and this is an important element of fisheries management policies to maintain the resilience of populations [20]. Thus, regular monitoring is necessary to detect changes in the reproductive potential of each stock.

Tuck et al. [4] suggested that adverse environmental conditions or a deprivation of sexual hormones may be responsible for female $N$. norvegicus resorbing their ovaries. Intensive fishing activity does not only affect populations directly but can also dramatically alter the environment. Bailey [10] found higher levels of ovary resorption in highly exploited populations of $N$. norvegicus when comparing them to less exploited populations. Possible explanations could be found in reduced oxygen levels, seabed disturbance and seismic or acoustic stress caused by human activity, especially trawling. Intensive lobster fisheries are also known to cause skewed sex-ratios if exploitation is sex-biased [7]. Depending on the season and the gear, commercial catches of $N$. norvegicus often have a strong male-bias [12]. The main reason for this is in the different burrow emergence behaviour of the two sexes due to reproductive constraints [21]. In UK waters, ovigerous females are incubating eggs from summer for 8-10 months over winter until larvae hatch in the following spring [22]. During incubation, female lobsters remain in their burrow for long periods of time and are, thus, less catchable than males, which emerge from their burrows more frequently and are therefore over-represented in the catches [7]. Several studies have reported seasonal differences in the sex-ratios of $N$. norvegicus in trawl catches with a male bias, especially during the winter months $[12,21]$.

One common assumption is that the number of females is more important for the reproductive potential of a population than the number of males, as the production of female eggs involves higher metabolic costs than the production of male sperm [11]. Females also produce eggs in much lower numbers than males produce spermatozoa, which are sometimes regarded as an 


\section{Additional samples North Sea (February 2017)}

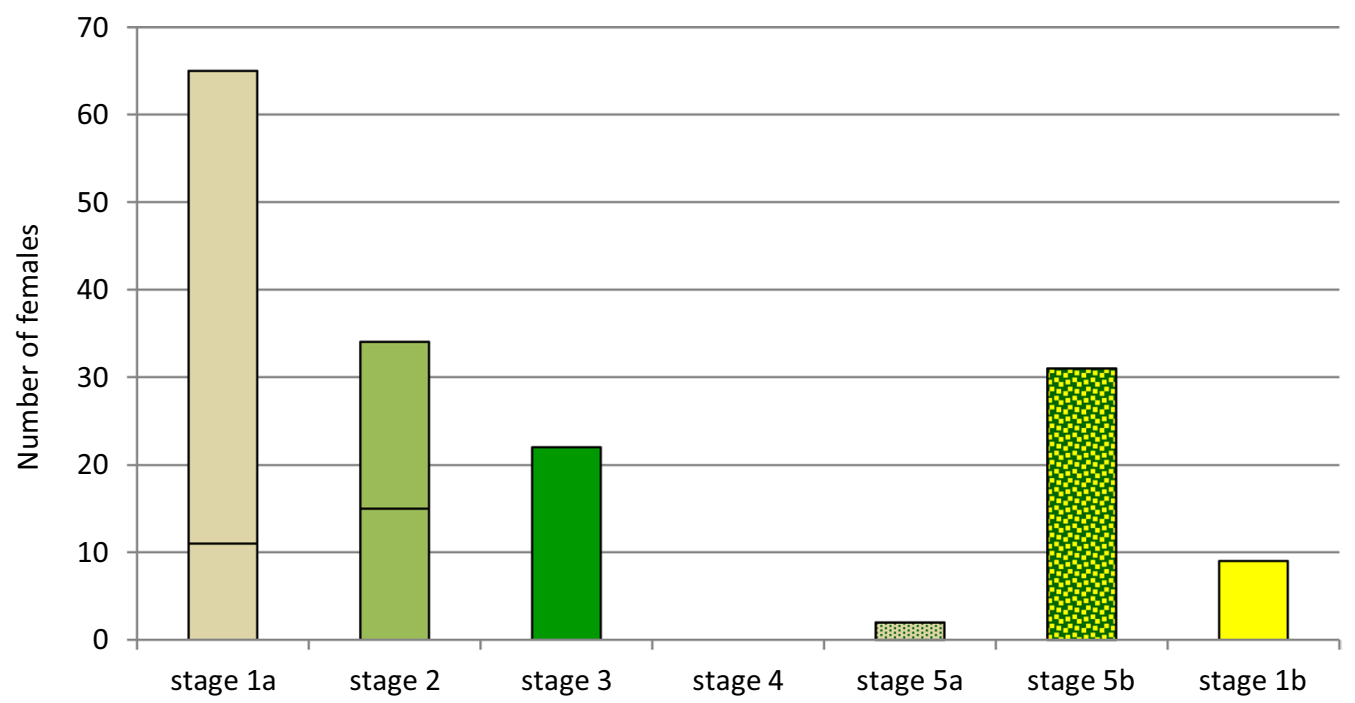

\section{Additional samples North Sea (March 2017)}

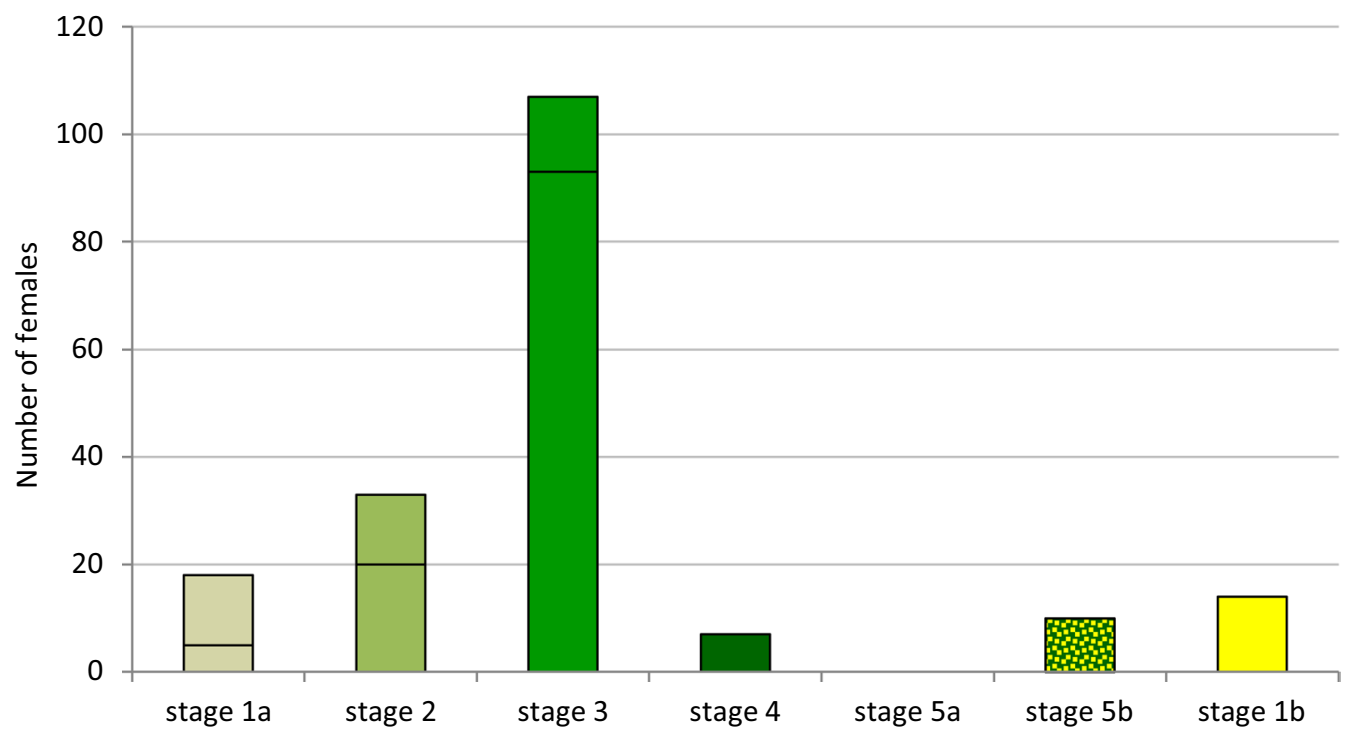

Fig. 5 Female Nephrops norvegicus maturity stages in samples from the Farn Deeps region of the North Sea from commercial catches in February and March 2017. A revised staging scale (following Becker et al. [5]) was adopted to assess maturity stages. Only adult females were represented in these commercial catches, sexually immature females (stage 0 ) are therefore absent. Ovaries of berried females were staged, the proportion of berried females in each stage is shown in the upper section of each column (if present). In February, a total of 163 females were assessed, 25\% of which had resorbing ovaries (stage 5b, 1b). In March, 13\% of 189 females showed ovaries under full resorption (stages 5b, 1b)

inexhaustible resource. However, several studies on decapod crustacean species using experiments in holding tanks have actually shown that sperm supply can become a limiting factor for the reproductive success of a population (e.g. Pseudocarcinus gigas [23]; Callinectes sapidus [24]; Hapalogaster dentata [25]; Chionoecetes opilio
[26]; Metacarcinus edwardsii [27]. Sperm availability in a population depends on several factors, e.g. post-mating sperm regeneration intervals in the male, sperm storage capacity in the female and the longevity of spermatozoa. The operational sex ratio is another important factor, as well as male and female size distributions if mating is size 


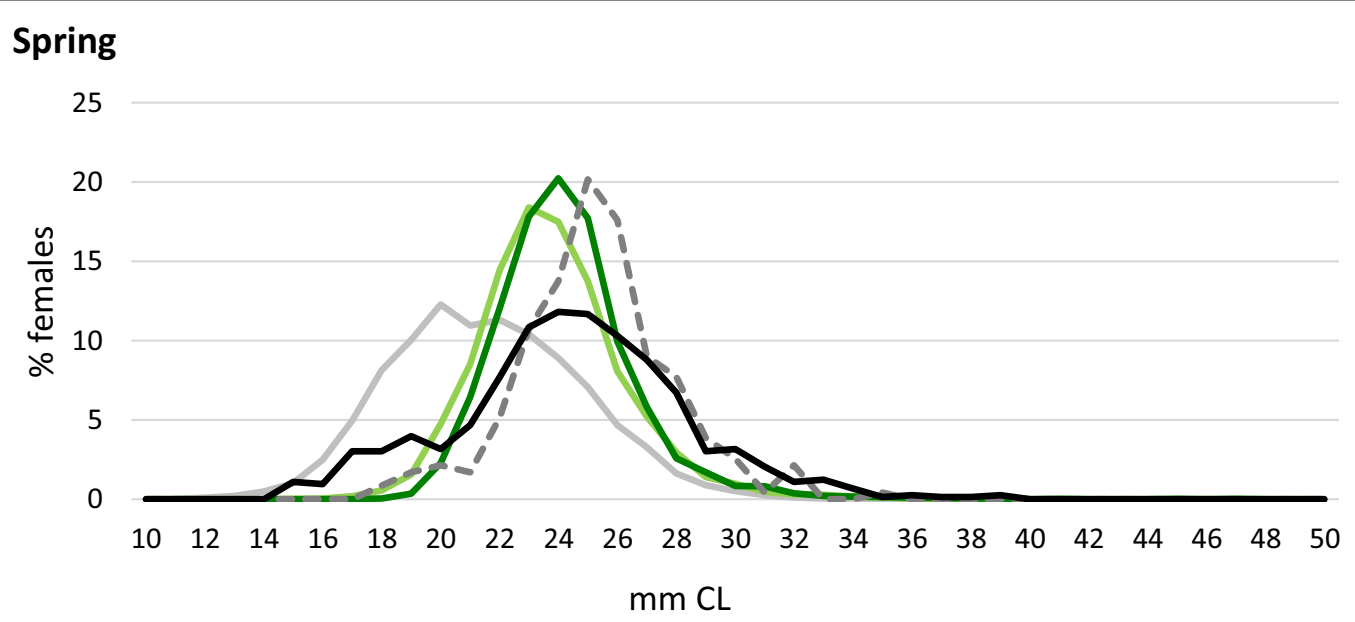

\section{Summer}

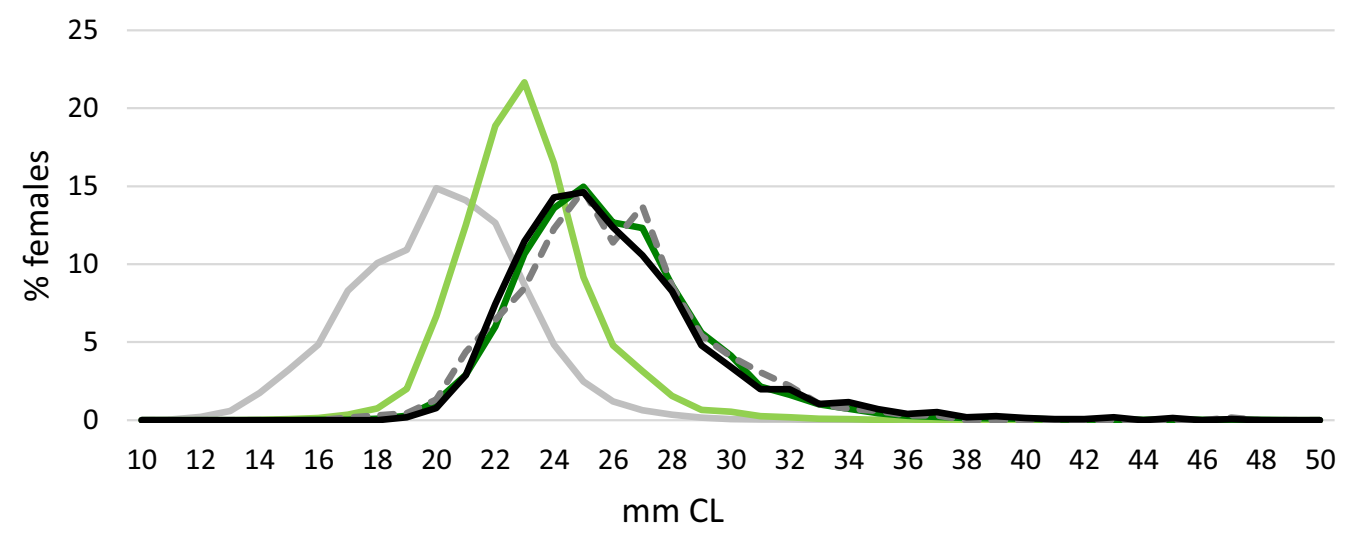

\section{Autumn}

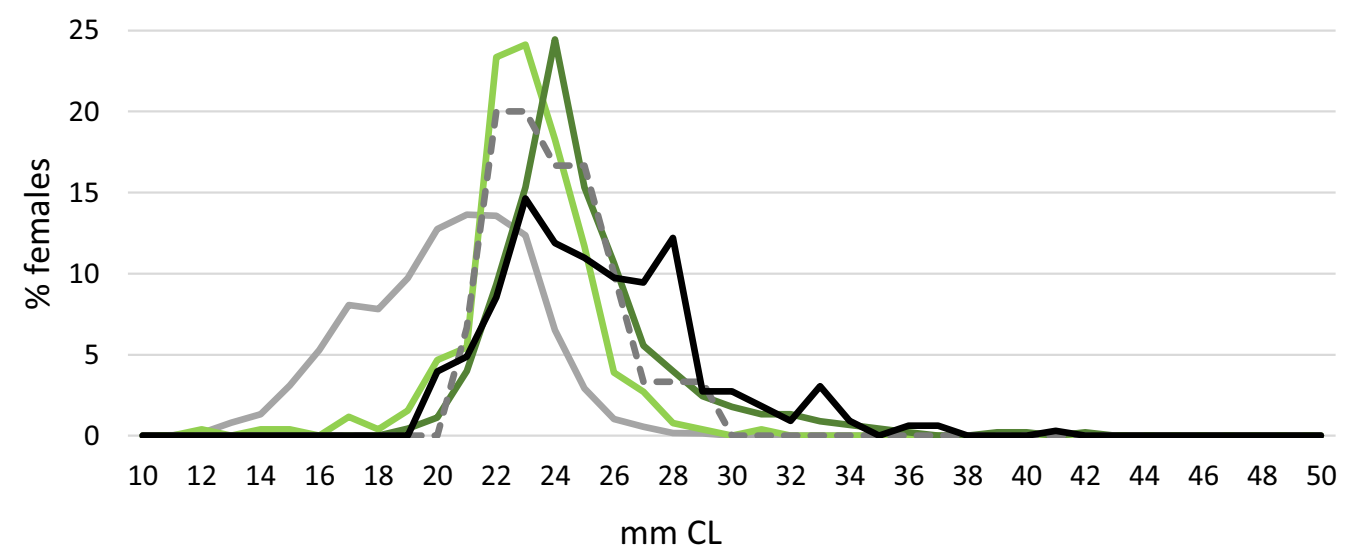

stage $0 / 1 \mathrm{a} \longrightarrow$ stage $2 \longrightarrow$ stage $3 / 4$ - stage $5 \mathrm{~b} \longrightarrow$ berried

Fig. 6 Size distribution of female Nephrops norvegicus in different ovary maturation stages in different seasons from samples collected by the Agri-Food and Biosciences Institute in the western Irish Sea from 1994 to 2016 


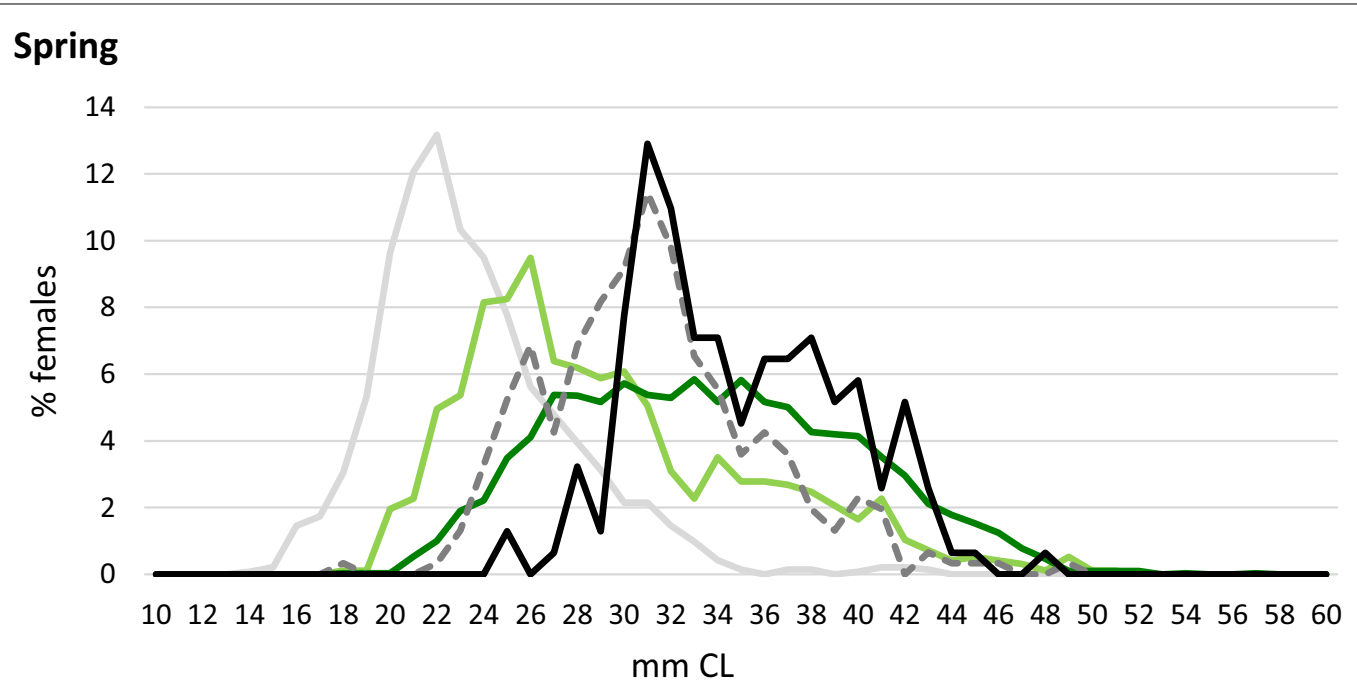

\section{Autumn}

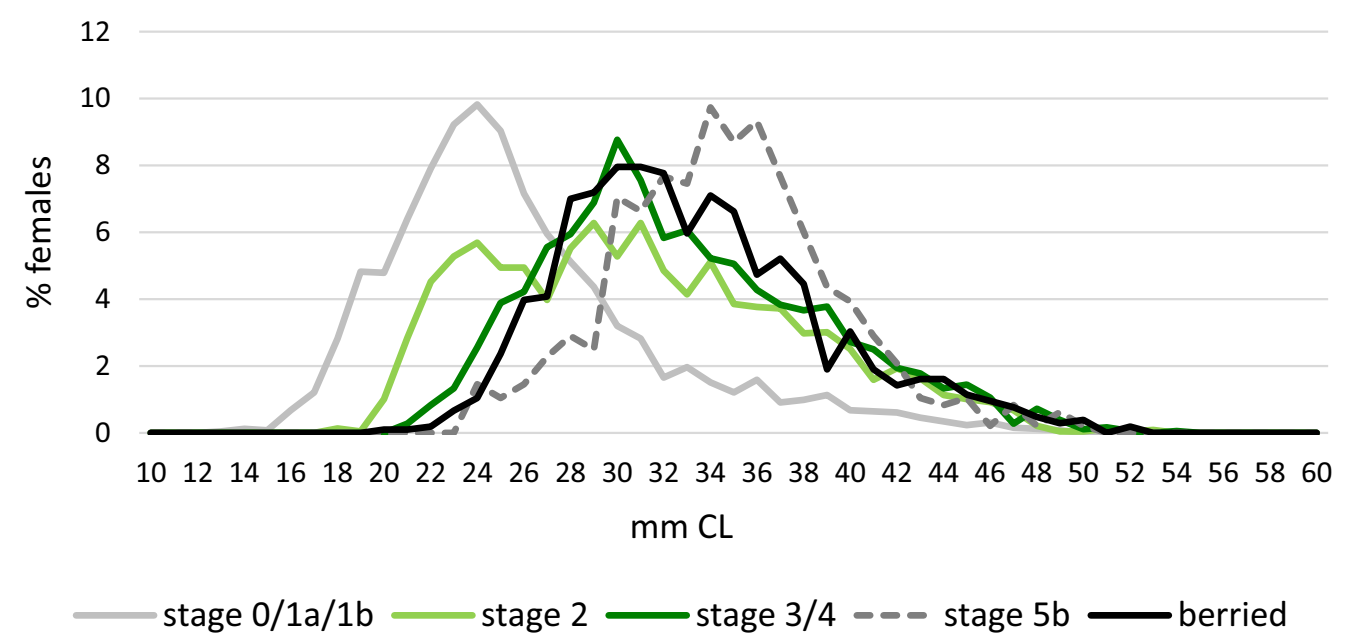

Fig. 7 Size distribution of female Nephrops norvegicus in different ovary maturation stages in spring and autumn respectively from samples collected by the Centre of Environment, Fisheries and Aquaculture Science in the Farn Deeps of the North Sea from 1998 to 2017

assortative as in several other decapod crustaceans [28, 29]. The idea that ovary resorption in N. norvegicus may be due to a lack of insemination has been brought forward by several authors $[4,10]$. De Figueiredo [8] studied the frequency of resorption in two populations of $N$. norvegicus off the Atlantic coast of Portugal (Alentejo and Algarve). She did not find a correlation between the percentage of females with resorbing ovaries and the incidence of females with empty spermatheca. However, this earlier study did not examine whether individual females with resorbing ovaries were inseminated. Our study therefore presents the first direct test of whether females of $N$. norvegicus with resorbing ovaries are actually inseminated. Our results show that a lack of insemination is not the cause for ovary resorption in $N$. norvegicus; all mature females studied herein carried spermatophores in their spermathecae and, thus, had mated.

\section{Mating and sperm storage}

Copulation in N. norvegicus is initiated by a brief courtship, followed by the transfer of ejaculate by the male gonopods which takes a few seconds only (CB pers. obs.). Sperm is assumed to be shed with the cuticle of the spermatheca when moulting. Thus, moulting and mating are closely linked and females need to re-mate each ovarian cycle. Herein, we present the first direct evidence of the loss of stored sperm during ecdysis, which is apparent in the complete shedding of the cuticle of the spermatheca. 

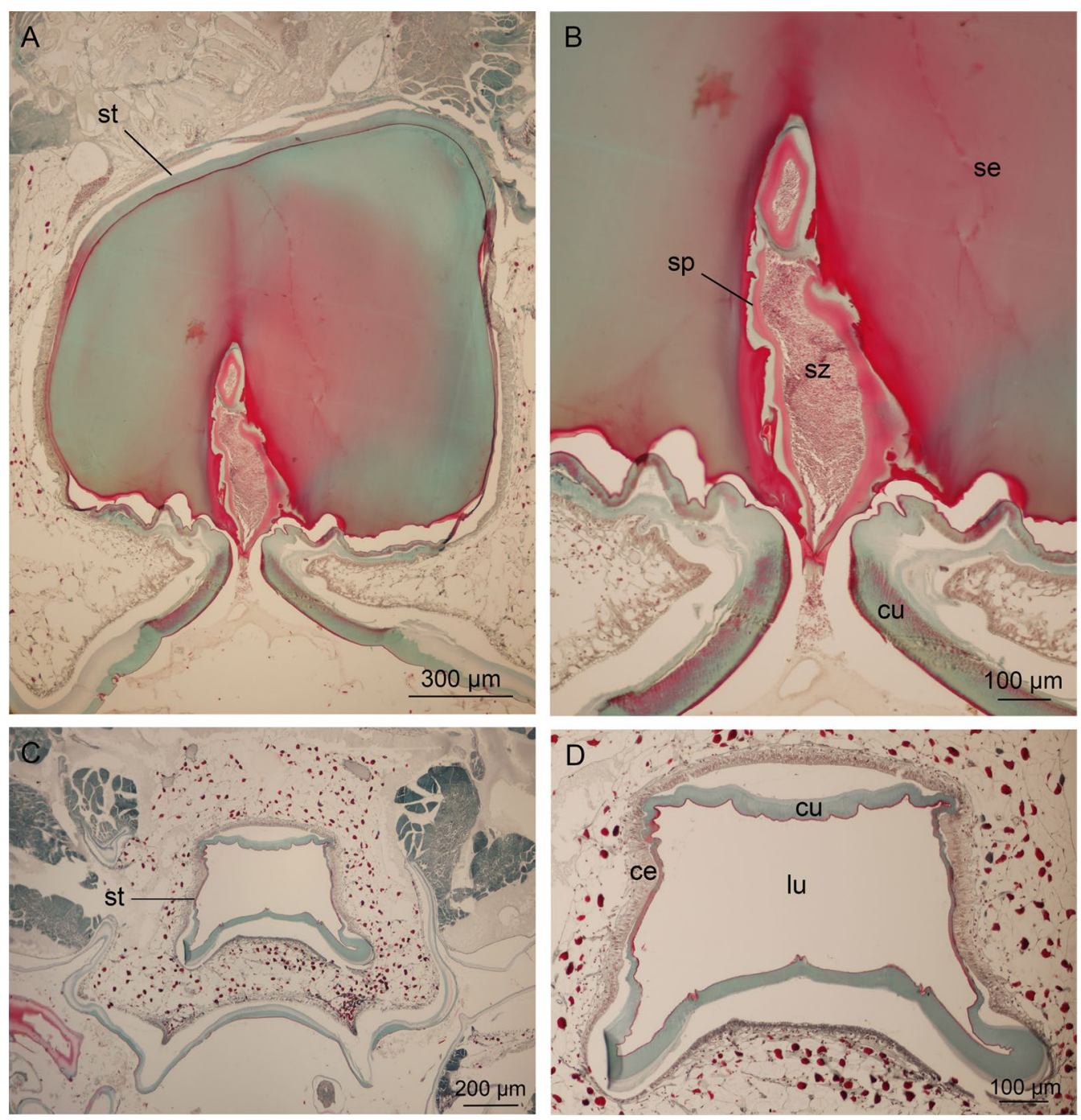

Fig. 8 Light micrographs (trichromatic Masson-Goldner from transverse sections of female Nephrops norvegicus sperm storage organ (termed spermatheca). a, b Spermatheca of a mature female showing spermatozoa encapsulated in a spermatophore surrounded by seminal fluid. $\mathbf{C}$ and D) Empty spermatheca of a juvenile female $(19 \mathrm{~mm} \mathrm{CL})$. The cuticle is delaminated from the underlying columnar epithelium in $\mathbf{c}$, $\mathbf{d}$. ce $=\mathbf{c o l u m n a r}$ epithelium, $\mathrm{cu}=$ cuticle, lu= lumen of spermatheca, $\mathrm{se}=$ seminal fluid (sperm plug), $\mathrm{sp}=$ spermatophore, $\mathrm{st}=\mathrm{spermatheca}, \mathrm{sz}=\mathrm{spermatozoa}$

Our study of a pre-moult female shortly before ecdysis shows that male seminal secretions functioning as a sealant and spermatophores are already degraded at this stage. Whether this is due to the forthcoming moult or a consequence of the last process of fertilization remains unknown. The actual process of fertilisation, i.e. how stored sperm is released from the spermatheca and where exactly oocytes become fertilised, as well the histology of the spermatheca at this stage, has not been studied in $N$. norvegicus. However, in $H$. americanus, the process of fertilization has been confirmed to happen externally [18]. Despite previous speculation that $N$. norvegicus may have internal fertilization [13], our data clearly suggests that the process of fertilization is external and probably very similar to $H$. americanus. In the latter species, the anterior suture is interpreted as the spermathecal orifice through which spermatophores enter the spermatheca during copulation while the two posterior sutures allow the spermatozoa to leave the spermatheca at the time of fertilization.

The morphology of the male internal reproductive organs of $N$. norvegicus has been studied previously [30], revealing a muscular sphincter between the middle and distal vas deferens which functions in portioning the sperm cord and its matrix into individual spermatophores. This sphincter may play an important role if 
males adjust the size and/or number of spermatophores they transfer during copulation. However, data on how many spermatophores are transferred to one female during copulation, is absent from the literature. Spermatophores are transferred together with vast amounts of seminal fluids, which harden and form a kind of sealant that occupies most of the space in the spermatheca. Such sealants are often interpreted as a mean to protect the male investment and may play an important role in sperm competition [19]. Several individual spermatophores embedded in distinct portions of sealants were apparent in most of the studied spermathecae of $N$. norvegicus. Such a layering of male ejaculates in female sperm storage organs indicates their origin from different males and, thus, suggests that females copulate with consecutive mates within one reproductive season [19].

Promiscuity in female $N$. norvegicus is also evident through paternity testing. Multiple paternity was observed in more than $50 \%$ of female clutches in a population off the Portuguese Atlantic coast. Two to three males contributed approximately evenly in the fertilization of ova [31]. Multiple paternity was also demonstrated in $H$. americanus [32] while broods of $H$. gammarus were found to be single-sired [33]. Multipaternity in $H$. americanus seems to be related to fishing intensity. At the Atlantic coast off Canada, multi-sired broods were observed in highly exploited populations while females from unexploited populations had singlesired broods [34]. Sperm limitation might therefore not necessarily lead to a lack of insemination in females per se, but increase the number of matings in females as the amount (or quality) of sperm decreases. Future studies may target this issue by studying the operational sex ratios and the degree of multiple paternity in $N$. norvegicus broods to reveal whether exploited populations show indication of sperm limitation.

\section{The incidence of ovary resorption and its seasonal dynamics}

The frequency of full ovary resorption (stage $5 b$ ) is highest once the spawning season passes in autumn, and stays high throughout winter until it ceases in spring. This seasonality was evident in data from the Farn Deeps in the North Sea and agrees with the pattern observed in populations off the Portuguese Atlantic coast [8]. The seasonal pattern of full ovary resorption may also explain the low levels of resorption observed in the western Irish Sea where most samples were taken in spring and summer. The highest proportion of resorbing females at $25 \%$ was observed in the additional samples from the Farn Deeps region where stages were assessed using a revised staging scale based on the incorporation of macroscopic and microscopic observations [5]: bright yellow ovaries showed signs of resorption microscopically and represent a very progressed stage of resorption after all the green yolk is already reabsorbed (stage 1b). Those ovaries had not been recognised as a separate stage in the maturity scales adopted by AFBI and CEFAS. The actual proportion of females undergoing resorption may therefore be higher than the incidence detectable in their data. De Figueiredo [8] found even higher frequencies of resorbing ovaries $(>80 \%)$ in $N$. norvegicus populations off the Atlantic coast of Portugal.

Assuming an annual reproductive cycle, the majority of mature females should carry eggs in the season where incubation takes place (summer to spring in the following year). The natural proportion of berried females cannot be drawn from collected data as berried females are believed to remain in their burrows most of the time, and thus, are under-represented in catches [12]. Nevertheless, the high incidence of large (mature) females, without clutches, in samples from the North Sea during the incubation period, may indicate that in this area there is an increased prevalence of females that had undergone resorption previously and already re-entered the regular ovary maturation cycle.

\footnotetext{
(See figure on next page.)

Fig. 9 The detailed anatomy of the sperm storage organ (spermatheca) in inseminated female Nephrops norvegicus (b-h: Light micrographs of histological sections stained with trichromatic Masson-Goldner). Several spermatophores are observed in different areas of the spermatheca. a Macrograph of the ventral side of the female sternum showing the spermathecal orifice formed by an anterior central suture (as) and two posterior sutures (ps) between sternites 7 and 8 . The gonopores (go) are located on the coxae of the third pereiopods (P3). Orientation of histological transverse sections through the spermatheca in B-D are indicated by dotted lines in the inset image. $\mathbf{a}, \mathbf{b}$ Section through the large anterior storage area of the spermatheca on the level of the anterior central suture (as). $\mathbf{c}$ In the middle part, the spermatheca is constricted by sternite 8 . $\mathbf{d}$ The spermatheca forms two separate processes most posteriorly filled with spermatophores. $\mathbf{e}$, $\mathbf{f}$ Details of spermatophores located in the posterior processes of the spermatheca. $\mathbf{g}, \mathbf{h}$ Spermatheca in a female prior to ecdysis. The old cuticle consisting of endocuticle and exocuticle and a thin red-staining epicuticle is delaminated from the newly formed exocuticle. Spermatophores are disintegrated and a spermatophore wall is no longer developed. $7=$ sternite $7,8=$ sternite 8 , as $=$ anterior central suture, eg $=$ eggs, en $=$ endocuticle, ex $=$ exocuticle, $\mathrm{go}=$ gonopore, $\mathrm{mu}=$ musculature, $\mathrm{nc}=$ new cuticle, $\mathrm{oc}=$ old cuticle, $\mathrm{P}=$ pereiopods, $\mathrm{ps}=$ posterior suture, $\mathrm{se}=$ seminal fluid, $\mathrm{sp}=\mathrm{spermatophore}$ st $=$ spermatheca, $\mathrm{sw}=$ spermatophore wall
} 

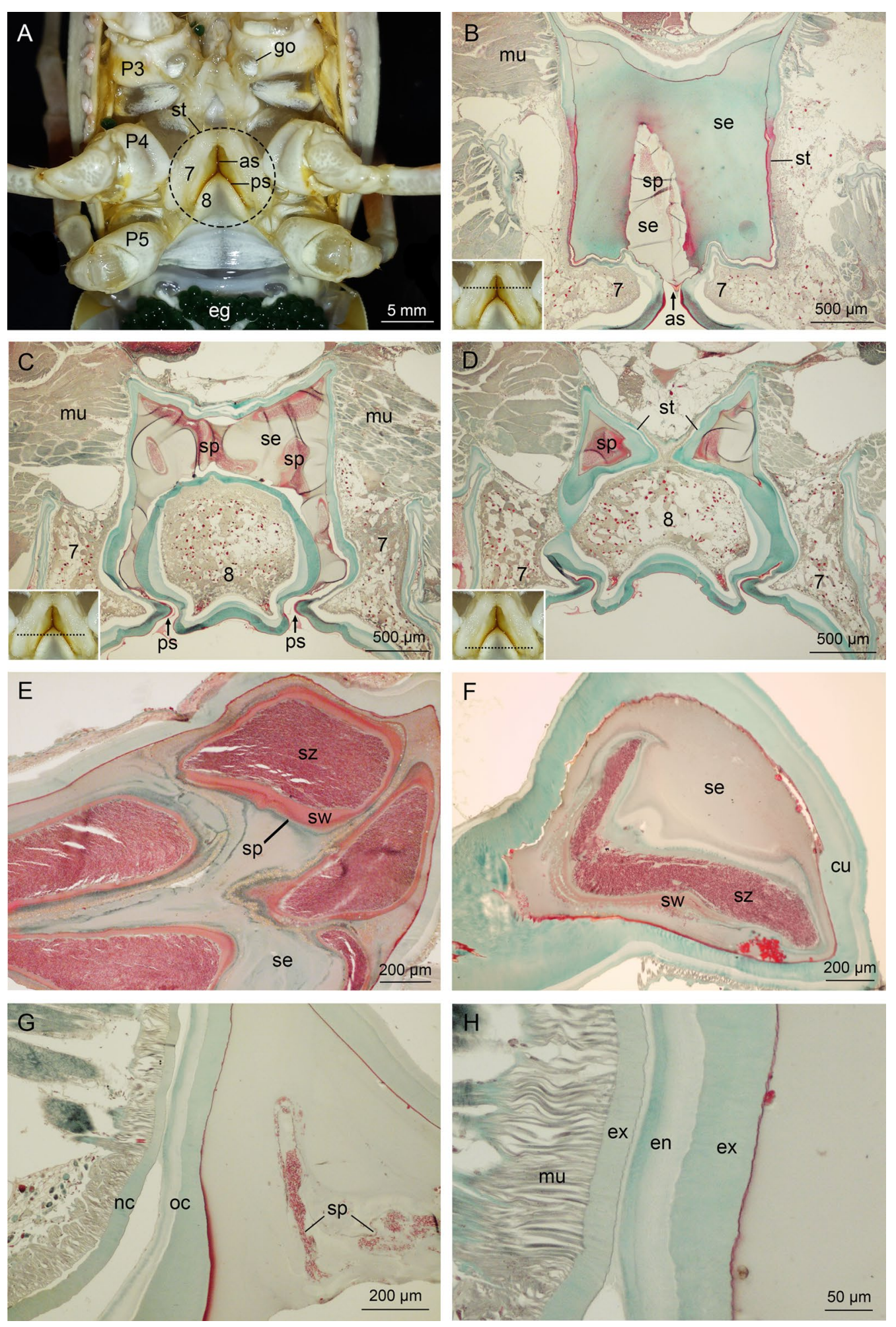


\section{Ovary resorption and female body size}

If full ovary resorption was more frequent in smaller females, one could hypothesize that it mainly occurs in females that start maturing for the first time. The first onset of sexual maturity does not seem to occur at a specific season of the year [35]. As a result, the first reproductive cycle of young females is not in synchrony with the regular seasonal reproductive cycle of other (older) sexually mature females. The first maturation of the ovary may therefore not lead to a successful spawning but could be regarded as a test run which may also lead to full ovary resorption if ovary maturation is not completed until spawning season. However, this is not supported by our data. According to the interpretation of Bailey [10] that full ovary resorption is a "reset the clock"-strategy of larger (older) females, the occurrence of resorption should be positively correlated with body size. This was supported by data on $N$. norvegicus $[10,36]$ collected off the west coast of Scotland (Sound of Jura and Firth of Clyde). The study in the Firth of Clyde further supported Bailey's hypothesis as the length frequency curves developed in his study indicate that the reproductive cycle may take longer than a year [36]. However, a negative correlation was found between ovary resorption and body size off the West coast off Portugal [8]. Our analysis support Bailey's hypothesis only with regard to females from the Farn Deeps region in the North Sea-where resorption was high-but not in females from the western Irish Sea. The latter populations show in general smaller body sizes than specimens from the North Sea (see Additional file 3: Fig. S2). This may not only explain that body size did not show a positive correlation with the frequency of ovary resorption, but also be responsible for the total proportion of resorption being very low $(<1 \%)$ in the western Irish Sea populations. Furthermore, the timing of the surveys conducted in the western Irish Sea (summer) was unsuitable to assess the degree of full ovary resorption as the highest frequency is expected later in the year, once the spawning season has passed in autumn.

As in many decapod crustaceans, the reproduction, or at least the reproductive cycle of females, is linked with the moult cycle. Females moult after larvae have hatched from the clutch and mate immediately afterwards, while their exoskeleton is still soft ("soft-shelled mating" [11]). Many decapods show this type of moulting and mating link [11,37]. However, copulation can also occur in intermoult females ("hard-shelled mating" [11]) and some decapod species show both pathways (e.g. [26]). Another important factor with regard to the timing of the female moult is the period of incubation. The clutch of eggs attached to female pleopods, would be lost when the exoskeleton is shed at ecdysis. As incubation takes approximately up to 9 months in western Irish Sea and
North Sea N. norvegicus populations, moulting of berried females can only occur within the short time frame between hatching and spawning of the next generation. Based on the morphology of the spermatheca in a premoult female, it seems likely that the discharging of the spermathecal content is necessary to receive and store fresh spermatophores for the next reproductive cycle. Thus, moulting must occur at a set point of time in reproductively active females. Males are known to be more flexible about the timing of ecdysis and moult more frequently than females [12]. As a consequence, males grow faster and are on average larger than females of the same (supposed) age [35]. Resorbing their ovaries and skipping a reproductive cycle from time to time may allow females more flexibility in terms of moulting and, thus growth. This leads us to the question whether females actually resorb because they are larger or if females are larger because they resorb.

\section{Conclusions}

Results of the present study can clearly refute that full ovary resorption in $N$. norvegicus is caused by the absence of insemination in affected females, however, insights on the quantity and quality of sperm females receive may yet play a role in the phenomenon of resorption. Whether ovary resorption affects the lifetime fecundity of females and thereby the reproductive capacity of stocks remains unknown. Indeed, resorption may be an adaptation that does not reduce the fecundity if producing larger clutch sizes by larger females outweighs the costs of skipping a reproductive cycle every couple of years. It remains unknown which factors trigger a female's "decision" to resorb the ovary instead of spawning; water temperature and light schedules may play a role in this process. In this regard, ovary resorption may constitute a natural phenomenon in $N$. norvegicus.

In contrast to earlier approaches [13, 38], the reproductive capacity of $N$. norvegicus populations cannot be determined from the proportion of females with mature ovaries at a given season. With regard to the high levels of ovary resorption observed in some populations of $N$. norvegicus, not all sexually mature females produce eggs every year and contribute to the spawning stock. The larval production of populations comprising a substantial proportion of large females may be lower than expected if these animals have higher resorption rates. This has potential repercussions for fishery management where target fishing mortalities are extrapolated from estimates of population function in unexploited situations (so called "virgin" states). It is therefore important to research the mechanisms driving resorption rates to ensure that the fishery management targets are robust to such events. 
The present study contributes an advance in the science required for effective fisheries management through detailed anatomical studies. This is an example of how fundamental investigations into the biology of target species can effectively underpin the evidence-based management required to achieve sustainable fisheries.

\section{Supplementary information}

Additional file 1: Fig. S1. Map showing grid of stations sampled by the Agri-Food and Biosciences Institute (AFBI) in the western Irish Sea from 1994-2016. Not all stations are samples each year. Additional file 2:

Table S2. List of specimens used for dissections and microscopic analysis. $\mathrm{CL}=$ carapace length.

Additional file 3: Fig. S2. Stations sampled by the Agri-Food and Biosciences Institute in the western Irish Sea between 1994 and 2016.

Additional file 4: Table S1. Mean sizes of females in different stages in the western Irish Sea and the Farn Deeps respectively.

\section{Acknowledgements}

The funding for this project was received from Seafish and Kilkeel/Whitby Seafoods. We especially thank Lynn Gilmore, Phil McMullan and William Lart (Seafish), and Daniel Whittle (Kilkeel/Whitby Seafoods) for their help and advice throughout the project.

\section{Authors' contributions}

JDS, JTAD and CB planned and coordinated the study. Data have been collected by CB, Agri-Food and Biosciences Institute and Centre of Environment, Fisheries and Aquaculture Science. CB and JDS have analysed the data. CB and JDS have prepared the manuscript. All authors read and approved the final manuscript.

\section{Funding}

This study was funded by the UK Sea Fish Industry Authority's (Seafish) Strategic Investment Programme and Kilkeel/Whitby Seafoods (U.K.) (Grant Number SR-7941610).

\section{Availability of data and materials}

Specimens, samples and data used in this study are deposited at Queen's Marine Laboratory, Portaferry, UK. The data sets used in this study are available from the corresponding author on reasonable request.

\section{Ethics approval and consent to participate}

The conducted research adhered to legal requirements for animal care in the European Union.

\section{Consent for publication}

Not applicable.

\section{Competing interests}

None of the authors have any competing interests in the manuscript.

\section{Author details}

1 Queen's University Marine Laboratory, 12-13 The Strand, Portaferry BT22 1PF, Northern Ireland, UK. ${ }^{2}$ Institute for Global Food Security, School of Biological Sciences, Queen's University Belfast, MBC, 97 Lisburn Road, Belfast BT9 7BL, Northern Ireland, UK. ${ }^{3}$ Agri-Food and Biosciences Institute, 18a Newforge Lane, Belfast BT9 5PX, Northern Ireland, UK. ${ }^{4}$ Centre of Environment, Fisheries and Aquaculture Science, Pakefield Road, Lowestoft, Suffolk, England, UK.

Received: 1 August 2019 Accepted: 8 October 2020

Published online: 27 October 2020

\section{References}

1. Allen EJ. The reproduction of the lobster. J Mar Biol Assoc UK. 1895;4:60-9.

2. Aiken DE, Waddy SL. Reproductive biology. In: Cobb JS, Phillips BF, editors. The biology and management of lobsters. Boston: Academic Press; 1980. p. 215-76.

3. Sastry AN. Ecological aspects of reproduction. In: Vernberg FJ, Vernberg WB, editors. The biology of Crustacea: 8 . Environmental adaptations. New York: Academic Press; 1983. p. 179-270.

4. Tuck ID, Taylor AC, Atkinson RJA, Gramitto ME, Smith C. Biochemical composition of Nephrops norvegicus: changes associated with ovary maturation. Mar Biol. 1997;129:505-11.

5. Becker C, Cunningham EM, Dick JTA, Eagling LE, Sigwart JD. A unified scale for female reproductive stages in the Norway lobster (Nephrops norvegicus): evidence from macroscopic and microscopic characterization. J Morph. 2018;279:1700-15.

6. Talbot P. Helluy S (1995) Biology of the lobster Homarus amercianus. In: Factor JR, editor. Biology of the lobster. Cambridge: Academic Press; 1995. p. 177-216.

7. MacDiarmid AB, Sainte-Marie B. Reproduction. In: Phillips BF, editor. Lobsters: biology, management, aquaculture and fisheries. Oxford: Blackwell Publishing Ltd; 2006. p. 45-77.

8. de Figueiredo MJ. The occurence of resorbtion in the ovaries Nephrops norvegicus (L.) in Portuguese waters. ICES Shellfish Comm Doc CM. 1982:K28:1-7.

9. Herrick FH. Natural history of the American lobster. Bull Bur Fish. 1909;19:149-408.

10. Bailey N. Some aspects of reproduction in Nephrops. ICES Shellfish Comm Doc CM. 1984;K33:1-15.

11. McLay C, Becker C. Reproduction in Brachyura. In: Castro P, Davie PJF, Guinot D, Schram FR, von Vaupel Klein JC, editors. Decapoda-Brachyura Vol 9, Part C-I. Leiden: Brill; 2015. p. 185-243.

12. Chapman CJ. Ecology of juvenile and adult Nephrops. In: Cobb JS, Phillips $\mathrm{BF}$, editors. The biology and management of lobsters. Boston: Academic Press; 1980. p. 143-78.

13. Farmer ASD. Reproduction in Nephrops norvegicus (Decapoda: Nephropidae). J Zool London. 1994;174:161-83.

14. Symonds DJ. The fishery for the Norway lobster, Nephrops norvegicus (L) off the north-east coast of England. Fishery Investig. 1972;27:1-35.

15. Eiríksson H (2014) Reproductive biology of female Norway lobster, Nephrops norvegicus (Linnaeus, 1758) Leach, in Icelandic waters during the period 1960-2010. Comparative overview of distribution areas in the northeast Atlantic and the Mediterranean. In: Lesser M, editor. Advances in Marine Biology. Oxford: Elsevier; 2014. p. 65-210.

16. ICES. Report of the working group on Nephrops surveys (WGNEPS), 5-8 November 2013, Barcelona, Spain; International Council of the Exploration of the Sea, ICES CM 2013/SSGESST:21:1-27.

17. ICES. Report of the ICES Working Group on Nephrops stocks. WGNEPH Rep. 2004;2004:1-435.

18. Aiken DE, Waddy SL, Mercer SM. Confirmation of external fertilization in the American lobster, Homarus americanus. J Crust Biol. 2004;24:474-80.

19. Becker C, Bauer RT. Multiple matings and sperm competition. In: Cothran R, Thiel M, editors. The Natural History of Crustacea VI Reproductive Biology. New York: Oxford University Press; 2020. p. 332-63.

20. Orensanz JM, Armstrong J, Armstrong D, Hilborn R. Crustacean resources are vulnerable to serial depletion - The multifaceted decline of crab and shrimp fisheries in the Greater Gulf of Alaska. Rev Fish Biol Fish. 1998;8:117-76.

21. Mente E, Karapanagiotidis IT, Logothetis P, Vafidis D, Malandrakis E, Neofitou N, Exadactylos A, Stratakos A. The reproductive cycle of Norway lobster. J Zool. 2009;278:324-32.

22. Powell A, Eriksson SP. Reproduction: life cycle, larvae and larviculture. In: Johnson ML, Johnson MP, editors. Advances in marine biology. The ecology and biology of Nephrops norvegicus. London: Elsevier; 2013. p. 201-45.

23. Gardner $\mathrm{C}$, Williams H. Maturation in the male giant crab, Pseudocarcinus gigas, and the potential for sperm limitation in the Tasmanian fishery. Mar Freshw Res. 2002;53:661-7.

24. Hines AH, Jivoff PR, Bushmann PJ, Van Montfrans J, Reed SA, Wolcott DL, Wolcott TG. Evidence for sperm limitation in the blue crab, Callinectes sapidus. Bull Mar Sci. 2003;72:287-310. 
25. Sato T, Goshima S. Impacts of male-only fishing and sperm limitation in manipulated populations of an unfished crab, Hapalogaster dentata. Mar Ecol Prog Ser. 2006;313:193-204.

26. Sainte-Marie B, Gosselin T, Sévigny JM, Urbani N. The snow crab mating system: opportunity for natural and unnatural selection in a changing environment. Bull Mar Sci. 2008;83:131-61.

27. Pardo LM, Rosas Y, Fuentes JP, Riveros MP, Chaparro OR. Fishery induces sperm depletion and reduction in male reproductive potential for crab species under male-biased harvest strategy. PLOS ONE. 2015;10:e0115525. https://doi.org/10.1371/journal.pone.0115525.

28. Goshima S, Minouchi S, Yoshino K, Wada S. Size assortative mating by the hermit crab Pagurus filholi (Decapoda: Anomura: Paguridae). Crust Res Special Issue. 2006;6:87-94.

29. Fazhan H, Waiho K, Wan Norfaizza WI, Megat FH, Ikhwanuddin M. Assortative mating by size in three species of mud crabs, genus Scylla De Haan, 1833 (Brachyura: Portunidae). J Crust Biol. 2017;37:654-60.

30. Rotllant G, Chiva M, Durfort M, Ribes E. Internal anatomy and ultrastructure of the male reproductive system of the Norway lobster Nephrops norvegicus (Decapoda: Astacidea). J Morph. 2012;273:572-85.

31. Streiff R, Mira S, Castro M, Cancela ML. Multiple paternity in Norway lobster (Nephrops norvegicus L.) assessed with microsatellite markers. Mar Biotechnol. 2004;6:60-6.

32. Jones MW, O'Reilly PT, McPherson AA, McParland TL, Armstrong DE, Cox AJ, Spence KR, Kenchington EL, Taggart CT, Bentzen P. Development, characterisation, inheritance, and cross-species utility of American lobster
(Homarus americanus) microsatellite and mtDNA PCR-RFLP markers. Genome. 2003;46(1):59-69.

33. Ellis CD, Hodgson DJ, André C, Sørdalen TK, Knutsen H, Griffiths AGF. Genotype reconstruction of paternity in European lobsters (Homarus gammarus). PLoS ONE. 2015. https://doi.org/10.1371/journal.pone.01395 85.

34. Gosselin T, Sainte-Marie B, Bernatchez L. Geographic variation of multiple paternity in the American lobster, Homarus americanus. Mol Ecol. 2005; 14:1517-25.

35. Farmer ASD. Synopsis of biological data on Norway lobster Nephrops norvegicus (Linneaus, 1758). FAO Fisheries Synopsis. 1975;112:1-97.

36. Smith RSM. The biology of larval and juvenile Nephrops norvegicus (L.) in the Firth of Clyde. Dissertation. Glasgow University; 1987.

37. McLay CL, López Greco LS. A hypothesis about the origin of sperm storage in the Eubrachyura, the effects of seminal receptacle structure on mating strategies and the evolution of crab diversity: How did a race to be first become a race to be last? Zool Anz. 2011;250:378-406.

38. Thomas HJ. The spawning and fecundity of the Norway lobsters (Nephrops norvegicus L.) around the Scottish coast. ICES J Mar Sci. 1964;29:221-9.

\section{Publisher's Note}

Springer Nature remains neutral with regard to jurisdictional claims in published maps and institutional affiliations.
Ready to submit your research? Choose BMC and benefit from:

- fast, convenient online submission

- thorough peer review by experienced researchers in your field

- rapid publication on acceptance

- support for research data, including large and complex data types

- gold Open Access which fosters wider collaboration and increased citations

- maximum visibility for your research: over 100M website views per year

At BMC, research is always in progress.

Learn more biomedcentral.com/submissions 